\title{
VEINTE AÑOS DE PRODUCCIÓN HISTÓRICA SOBRE LA GUERRA CIVIL ESPAÑOLA (1975-1995): UNA APROXIMACIÓN BIBLIOMÉTRICA
}

\author{
María del Rosario Rulz Franco* y Serglo Rlesco Roche**
}

Resumen: Análisis cuantitativo e historiográfico de la producción histórica sobre la guerra civil española (1936-1939) a través de lo publicado en libros y publicaciones perídicas españolas e internacionales de 1975 a 1995, obtenido en bases de datos, catálogos, repertorios bibliográficos y bibliografías especializadas. A partir del análisis de los datos, se presentan resultados en los siguientes aspectos: producción por materias, producción por años, áreas geográficas más estudiadas, aspectos editoriales más destacados, valoración de revistas y autores más prolíficos.

Palabras clave: guerra civil; España; 1936-1939; análisis cuantitativo; análisis historiográfico; publicaciones periódicas; monografías.

\begin{abstract}
This study presents the quantitative and historiographic analysis of the historic production about the Spanish civil war (1936-1939) through Spanish and international books and journals from 1975 to 1995 , obtained from databases, catalogs, bibliographic indexes and specialised bibliographies. The analysis presents results in the following fields: production by subjects, productivity expressed in years, more studied areas, evaluation of the publications and the most prolific authors.

Key words: civil war; Spain; 1936-1939; quantitative analysis; historiographic analysis; journals; books.
\end{abstract}

\section{Introducción}

No hay duda alguna de que la guerra civil española es el tema más investigado de nuestra historia y uno de los más estudiados a nivel internacional. Por ello consideramos interesante analizar cualitativamente y, sobre todo, cuantitativamente la producción histórica tanto nacional como internacional de dicho acontecimiento histórico en un período cronológico concreto: 1975-1995, dado su considerable volumen y su alto valor historiográfico.

Prácticamente desde el cincuentenario del inicio de la guerra no han cesado de publicarse trabajos e investigaciones sobre aspectos generales y sectoriales de la historiografía sobre la guerra (1). Por ello, consideramos que el análisis bibliométrico (2) se presenta como un indicador imprescindible e inseparable de las valoraciones historiográficas a pesar de las reticencias, si bien cada vez menos numerosas, de los investigadores de las ciencias sociales y humanas en la utili-

\footnotetext{
* Area de Historia del Centro de Información y Documentación Científica (CINDOC), CSIC. Correo electrónico: mrruiz@pa.uc3m.es.

** Fac. de Geografía e Historia. Universidad Complutense de Madrid.

Recibido: 16-12-98; 2." versión 14-4-99.
} 
zación de métodos cuantitativos en sus disciplinas (3-8). La diversidad de fuentes consultadas así como el alto número de referencias recogidas en nuestro estudio ofrecen una muestra, a nuestro juicio lo suficientemente significativa, para la aplicación de los indicadores bibliométricos y la consideración de sus resultados. Un estudio de estas características conlleva algunas limitaciones propias de la naturaleza del tema y de la propia recopilación bibliográfica. A pesar de ello, consideramos plausible e interesante exponer los resultados porque, aunque no posean un rigor bibliométrico similar a los aplicables a otras ciencias, sí proporcionan datos necesarios para dar idea de las tendencias en los distintos aspectos estudiados en un sentido positivo.

\section{Fuentes y metodología}

El presente estudio se basa en la bibliografía sobre la guerra civil incluida dentro de la Serie Bibliografías de Historia de España (BIHES) publicada por el Centro de Información y Documentación Científica (CINDOC) del CSIC. En un total de 3.597 referencias se recogió la producción histórica sobre el tema en monografías y publicaciones periódicas nacionales e internacionales desde 1975 a 1995. La recopilación bibliográfica se hizo a partir de diversas fuentes caracterizadas por su variedad, se conjugaron las técnicas informáticas más modernas de recogida de información con las más tradicionales, y, por otra parte, su dispersión, ya que se hizo necesaria la consulta de múltiples fuentes con la intención de conseguir ser exhaustivos. Las fuentes utilizadas en la recogida de información para elaborar esta bibliografía han sido las siguientes.

a) Bases de datos y catálogos automatizados: Bibliografía española de la Biblioteca Nacional, Bibliografía General Española (Hlas), ISBN, Historical Abstract, REBIUN (Bibliotecas Universitarias), Humanities Source (EBSCO), Cd-ROM del CSIC (Base de datos ISOC, CIRBICL y CIRBICR), Ariadna (Biblioteca Nacional), Social Citation Index, Uncover y Current Citation (EBSCO).

b) Catálogos impresos: Catálogos y repertorios bibliográficos, principalmente el de la Biblioteca Nacional, el fndice Histórico Español de la Universidad de Barcelona, el catálogo del Centro de Investigaciones y Estudios Republicanos (CIERE) y bibliografías de monografías (9-10).

La heterogeneidad y los diferentes criterios de catalogación son los dos aspectos destacados de las fuentes, siendo frecuente encontrar monografías y artículos citados de distintas maneras y con diferentes nombres. Especialmente delicado resulta seguir el rastro de las publicaciones académicas —actas de congresos y tesis doctorales-, al no contar con bases de datos actualizadas y fiables - Teseo y SIGLE - o quedar, a menudo, olvidadas bajo la forma de publicaciones de carácter comercial que van apareciendo. Otra cuestión importante es la variedad tipologica de libros, puesto que bajo el nombre de "guerra civil» aparecen novelas y tesis doctorales; historias de batallas y repertorios bibliográficos; memorias y biografías, y así sucesivamente. La objetividad y cientificidad pretendida por muchos autores queda oscurecida por los intentos de exculpación o por la filiación ideológica de los autores. Pero no debemos 
tomar esto como una licencia para discernir entre lo que es útil y lo que no en un estudio de estas características. El debate sobre la relevancia historiográfica de unas u otras obras o artículos no entra dentro de los objetivos de este artículo. La inclusión, análisis y tratamiento de novelas, por ejemplo, junto con trabajos de carácter científico se debe a la consideración de las primeras como fuente literaria de primera mano para el investigador.

Una vez recopiladas todas las referencias, se inició el proceso de informatización de las mismas bajo el software de gestión de bases de datos Basis-Plus. El número de campos recogidos - autor, título, año de publicación, título de revista, identificadores y topónimos-, permite una gran variedad de elementos de recuperación e índices sobre los que aplicar los indicadores bibliométricos con suficientes garantías de fiabilidad. Para analizar los documentos incorporados a nuestra bibliografía, hemos utilizado una serie de indicadores bibliométricos. De esta forma analizaremos los siguientes aspectos: distribución por materias, con especial atención a los estudios locales y regionales; distribución por años, valorando las fluctuaciones existentes diacrónicamente; distribución por editoriales y revistas, productividad por autores y autorías compartidas.

\section{Análisis de la producción bibliográfica. Resultados}

\subsection{Análisis por dominio temático}

La clasificación temática, consensuada con los especialistas colaboradores de la bibliografía, está estructurada en trece grandes bloques temáticos, algunos de los cuales cuentan con una subclasificación necesaria dada su amplitud.

Como vemos en la tabla I, mostramos por separado libros y revistas en cifras totales y como un sólo número en los tantos por ciento. Somos conscientes de que relacionar libros con artículos de revistas no es una de las formas más ortodoxas de indicar algunas conclusiones, pero dada la heterogeneidad del corpus bibliográfico sí es una forma de aproximarse a cuáles son las tendencias más llamativas. En cualquier caso, si las cifras son muy dispares entre artículos y monografías tratamos de puntualizar por qué.

El primer aspecto a destacar es que entre cuatro de los trece bloques temáticos se reparten dos terceras partes del total de la producción. Son las memorias y ensayos, los aspectos culturales e intelectuales, la política en general y todo lo relativo a la dimensión internacional de la guerra.

Un segundo grupo de temas oscila entre el $14 \%$ y el $8 \%$ de la producción total y está formado por: lo social, los aspectos militares, las biografías de políticos y militares de la época, las historias generales y regionales y las cuestiones metodológicas en las que se incluyen los repertorios de fuentes. Podríamos hablar, finalmente, de un conjunto de temas menos tratados. Entre ellos se encuentran los momentos previos a la guerra, la economía española y las colectivizaciones.

Los trabajos de memorias y ensayos (19,9\%) ocupan el primer lugar. Las monografías doblan en este aspecto al número de artículos, al tratarse de un tema que pertenece más al ámbito de las editoriales comerciales que de las revistas. De todos modos, el elevado número de artículos sobre el tema (152) es muy reseñable. Estas 
Tabla I

Distribución temática de los trabajos

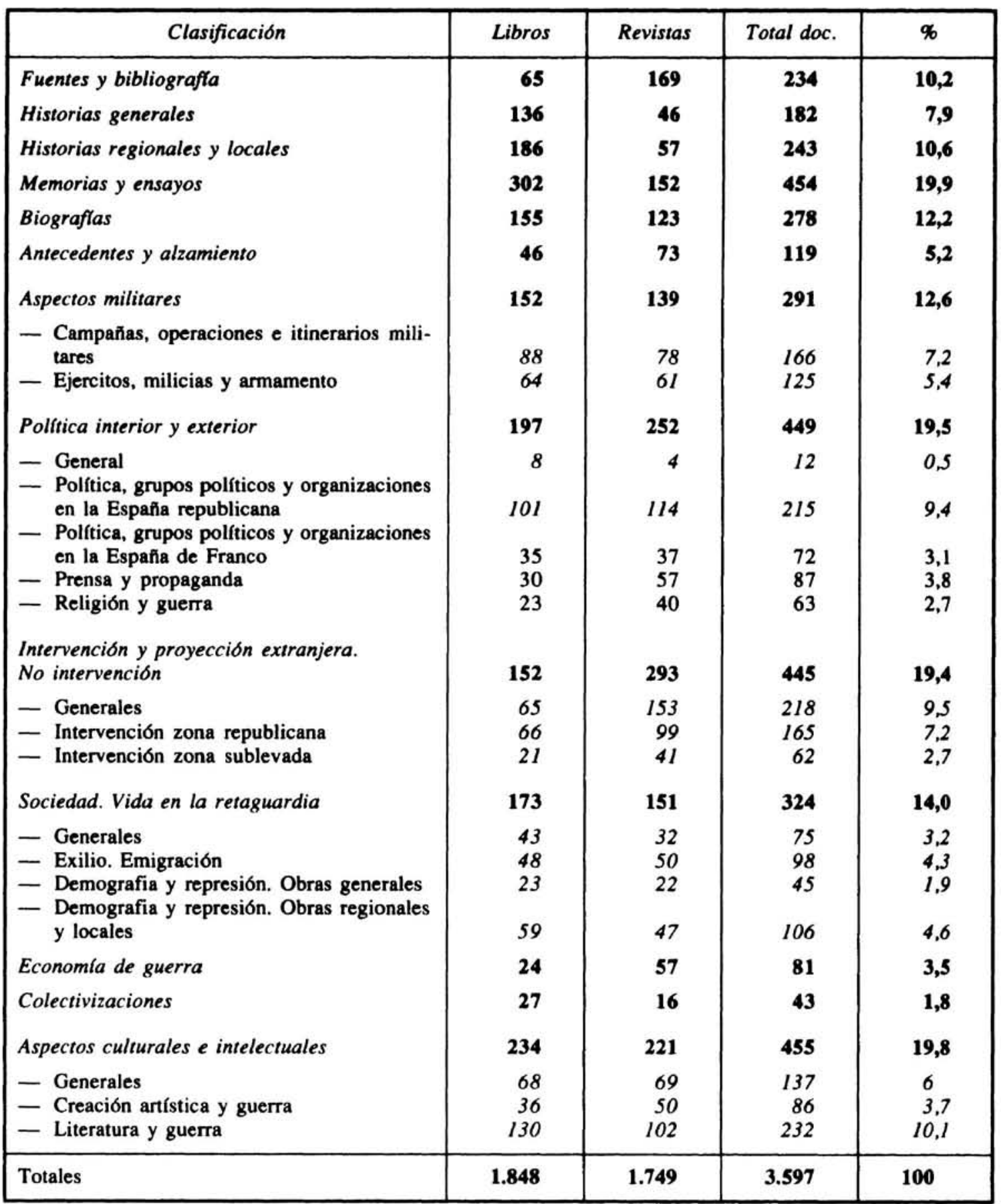

Fuente: «La guerra civil (1936-1939)», en Bibliograftas de Historia de España, n. ${ }^{\circ}$, Madrid, CINDOC (CSIC), 1996, 2 vols. 
memorias son muy variadas, coexistiendo todo tipo de ideologías y filiaciones. En la mayor parte de los casos se ahonda en las características bien conocidas de este género: autojustificación y autorrelevancia heroica.

La importancia de lo cultural en esta época está bastante comprobada. Buena parte de la construcción de nuestra memoria histórica se debe a las novelas ambientadas en la guerra civil o escritas a consecuencia de ella. Estos aspectos culturales e intelectuales constituyen un $19,8 \%$ de la producción, coincidiendo el número de libros y de revistas. Para una mayor homogeneización hemos unido las novelas - formato libro- a los aspectos de crítica e historia literaria que aparecen en ambos tipos. De ello resulta la mitad de ese casi $20 \%$ relativo a este eje temático. Tanto el arte (en un $3,7 \%$ ) como la cultura en general $(6 \%)$ forman parte de esta relación. Los trabajos sobre el famoso Congreso de intelectuales antifascistas de 1937 despuntan en esta línea. A nivel literario, predominan los estudios sobre la producción literaria de Federico García Lorca, George Orwell y Ernest Hemingway.

La proyección internacional del conflicto y la posición de los distintos países es el tercer aspecto de la guerra más analizado por los investigadores. Son estudios realizados principalmente en la década de los 80 y principios de los 90 , siendo el aspecto de la guerra que reúne más trabajos en revistas internacionales y el de mayor interés para los investigadores extranjeros. En todos los subgrupos en que se divide el epígrafe tienen una mayor representación los artículos de revista que los libros. Dentro del conjunto temático, hay una clara desproporción entre el número de trabajos referidos a la mera proyección internacional y la postura de no-intervención de algunos países $(9,5 \%$ ) y lo que fue la intervención -material, humana y económicaen ambos bandos. En esta última predominan los estudios que se centran en la ayuda a la República $(7,2 \%)$, en los que encontramos un alto porcentaje sobre las brigadas internacionales (115 trabajos), y, en menor medida, sobre la ayuda soviética. La historiografía soviética sobre la guerra tiene en Marklen T. Meshcheriakov y Jenö Gyorkei a sus principales representantes (11-15). En menor proporción numérica, los historiadores se han preocupado por la intervención de potencias extranjeras en la España sublevada $(2,7 \%)$, siendo de consulta necesaria para conocer la misma las obras ya clásicas de Angel Viñas o John F. Coverdale (16-17).

Las investigaciones que se centran en los aspectos políticos de los bandos en lucha presentan fuertes desequilibrios. El porcentaje de obras que analizan la política en general de ambos bandos en conjunto es muy bajo $(0,5 \%)$. Los estudios sobre la zona republicana $(9,4 \%)$ triplican a los existentes sobre la zona franquista $(3,1 \%)$. Esta desproporción radica en que la República en guerra ha sido uno de los temas preferidos de los historiadores que se han acercado a estudiar el conflicto; desde los órganos políticos del propio gobierno republicano, sus partidos y organizaciones, entre los que destacan la CNT -78 trabajos-, el POUM - 39- y el PCE -34-, hasta la justicia popular. Frente a ellos, han sido escasos $(3,1 \%)$ los estudios que se han centrado en los aspectos políticos de la España de Franco así como en los grupos y organizaciones de su zona. Los estudios sobre Falange son los que tienen mayor relevancia, destacando los de dos conocidos hispanistas: Stanley G. Payne y Sheelagh Ellwood (18-19). Cronológicamente hay que señalar que ambas zonas han sido estudiadas fundamentalmente en los años 80 y 90 , fechas en las que se abordan aspectos poco tratados hasta entonces sobre organizaciones y tendencias ideologicas. 
En la clasificación se optó por unir a este epígrafe general los trabajos, escasos, sobre prensa y propaganda $(3,8 \%)$ y sobre la cuestión religiosa durante la guerra $(2,7 \%)$. Esta línea de investigación presenta concordancia entre la cantidad de ambos tipos de publicaciones.

El apartado «Sociedad. Vida en la retaguardia» recoge todo lo relativo a la historia social. Nos encontramos con un número de monografías y artículos de revista de nuevo muy equilibrado. Ese $14 \%$ es el resultado de unir el exilio y la emigración $(4,3 \%)$; la represión con sus obras generales y regionales $(6,5 \%)$ y la vida en la retaguardia $(3,2 \%)$, así como la historia de las mujeres. Decidimos excluir de este apartado las colectivizaciones por la ambigüedad de las obras, que se mueven entre lo social y lo económico. Entre los trabajos de exilio y emigración, el primer estudio de importancia fue el libro de Javier Rubio (20). En lo que se refiere a las investigaciones sobre represión, abundan las referidas a zonas geográficas concretas $(4,6 \%)$, frente a las de ámbito nacional $(1,9 \%)$. Cabe resaltar, por su productividad y referencialidad, los trabajos de J. María Solé Sabaté y Joan Villarroya para la zona de Cataluña (21-22). Por su parte, son minoritarios los estudios que desde una perspectiva de género analizan la postura y la participación de las mujeres en la guerra, si bien en el ámbito político encontramos también libros al respecto como los pioneros de Mary Nash y Giuliana di Febo (23-24).

Los aspectos militares de la guerra $(12,6 \%)$ han atraído a un elevado número de investigadores. Las campañas y operaciones militares $(7,2 \%)$ predominan sobre aspectos monográficos del armamento utilizado por ambos bandos. La desigualdad es patente también en este apartado puesto que no todos los frentes, bombardeos o batallas han sido tratados por igual. Resaltan las veinticinco publicaciones sobre el bombardeo de Guernica. Las batallas sobre las que se tienen más referencias son las de Teruel (11), Madrid y Guadalajara (9). Tomando como unidad el concepto bélico de frente, el más estudiado es el de Madrid (29 trabajos), seguido de Aragón (16) y el del Norte (14).

Los estudios biográficos $(12,2 \%)$ se encuentran también sobradamente representados en libros y artículos. Nos encontramos con figuras muy estudiadas - Manuel Azaña, Francisco Franco- y con otras que aún siguen bastante ocultas - Juan Negrín, Emilio Mola- Cabe resaltar el interés de varios autores extranjeros por profundizar en esta temática, como por ejemplo Ian Gibson con José Antonio Primo de Rivera o Luigi Paselli con Manuel Azaña (25-26).

Una décima parte, en concreto un $10,2 \%$ de los trabajos, trata sobre fuentes y bibliografía. La publicación de investigaciones sobre este asunto en revistas triplica a los libros. Los materiales que se incluyen en estos estudios son muy variados: desde carteles y fotografías hasta trabajos sobre archivos pasando por temas de documentación periodística. En torno al cincuentenario del comienzo de la guerra aparecen numerosos estudios sobre secciones de archivos que se abren a los investigadores. Destacamos los particulares - como el de Manuel de Irujo o Luis de Araquistáin - y, sobre todo, lo relativo a la Sección Guerra Civil del Archivo Histórico Nacional en Salamanca. La obra más completa sobre fuentes tomadas en su conjunto que se ha publicado hasta la actualidad es la de Juan García Durán (10).

También han interesado los estudios que se han aproximado a analizar aspectos generales sobre la guerra civil pero circunscritos a espacios geográficos concretos regiones, ciudades y pueblos. Constituyen un $10,6 \%$ del total de la producción, abun- 
dando las monografías locales. Se trata de un tema que se impulsó desde el cincuentenario y que continúa teniendo mucha vigencia en la historiografía actual (27). Dada su relevancia, y como ya se ha indicado, hemos optado por tratar en un apartado específico esta cuestión de los estudios regionales y locales.

En menor medida, y fruto de ese interés localista al que nos acabamos de referir, encontramos un porcentaje inferior $(7,9 \%)$ de trabajos que abordan el conflicto de una manera nacional y global. A las obras conmemorativas publicadas con motivo del cincuentenario, se añaden los estudios ya clásicos de Hugh Thomas, Pierre Broué o Paul Preston (28-31).

Más minoritarios, aunque no por ello menos importantes, son los trabajos que analizan el alzamiento del 18 de julio y sus antecedentes $(5,2 \%)$, la economía de guerra $(3,5 \%)$ y las colectivizaciones $(1,8 \%)$. Entre los primeros son numerosas las investigaciones que se centran en los preparativos militares así como en los aspectos políticos del Frente Popular. Por su parte, los aspectos económicos del conflicto se encuentran totalmente descuidados (32), siendo necesaria aún en estas fechas la realización de estudios globales que nos ayuden a enmarcar mejor la situación económica del país (33). Esto contrasta con la existencia de este tipo de estudios para Cataluña y la Comunidad Valenciana. Estas dos comunidades son también las más estudiadas en el tema de las colectivizaciones, aspecto que se mueve entre la cuestión de la revolución social y la productividad de determinados sectores colectivizados. Las monografías regionales superan a los artículos. Especialmente signficativas en este ámbito regional son las obras de Aurora Bosch para la Comunidad Valenciana y de Anna Monjó y Carmen Vega para Cataluña (34-35).

\subsection{Estudios regionales y locales}

En el apartado sobre metodología hemos aclarado los criterios para la elaboración de este apartado. La comunidad autónoma como unidad administrativa nos permite ofrecer cuáles son las más y menos tratadas. La presencia masiva de estudios regionales y locales es una constante en la recopilación. Si bien en ella contábamos con 243 documentos específicos en el epígrafe «estudios regionales y locales», optamos ahora por un recuento de los topónimos de pueblos, ciudades y provincias y comunidades autónomas, que hemos convertido en porcentaje en aras de una mayor operatividad. Podemos observar los resultados en la figura 1. De un total de 3.597 documentos analizados, 1.308 mostraban algún topónimo, lo que representa un $36 \%$, o, en otras palabras, al menos uno de cada tres libros o artículos de revistas sobre la guerra civil cuenta con algun tipo de matiz regional o local.

Los resultados requieren algunas matizaciones similares a las procedentes de la distribución por campo temático. Debemos puntualizar que los resultados son interesantes pero han de ser observados cuidadosamente, pues, como es sabido, ni todas las comunidades autónomas son pluriprovinciales ni en todas fueron iguales la incidencia y duración de la guerra civil.

El primer hecho que llama la atención es ese $33 \%$ de Cataluña; uno de cada tres estudios regionales tiene como objeto esta comunidad. En los primeros años de la transición, los trabajos de Guarner o Rojas inauguraron una prolija producción a nivel regional. Debemos contar con la importancia del apoyo institucional en la recu- 


\section{Figura 1}

Distribución de los documentos por comunidades autónomas expresados en porcentaje*

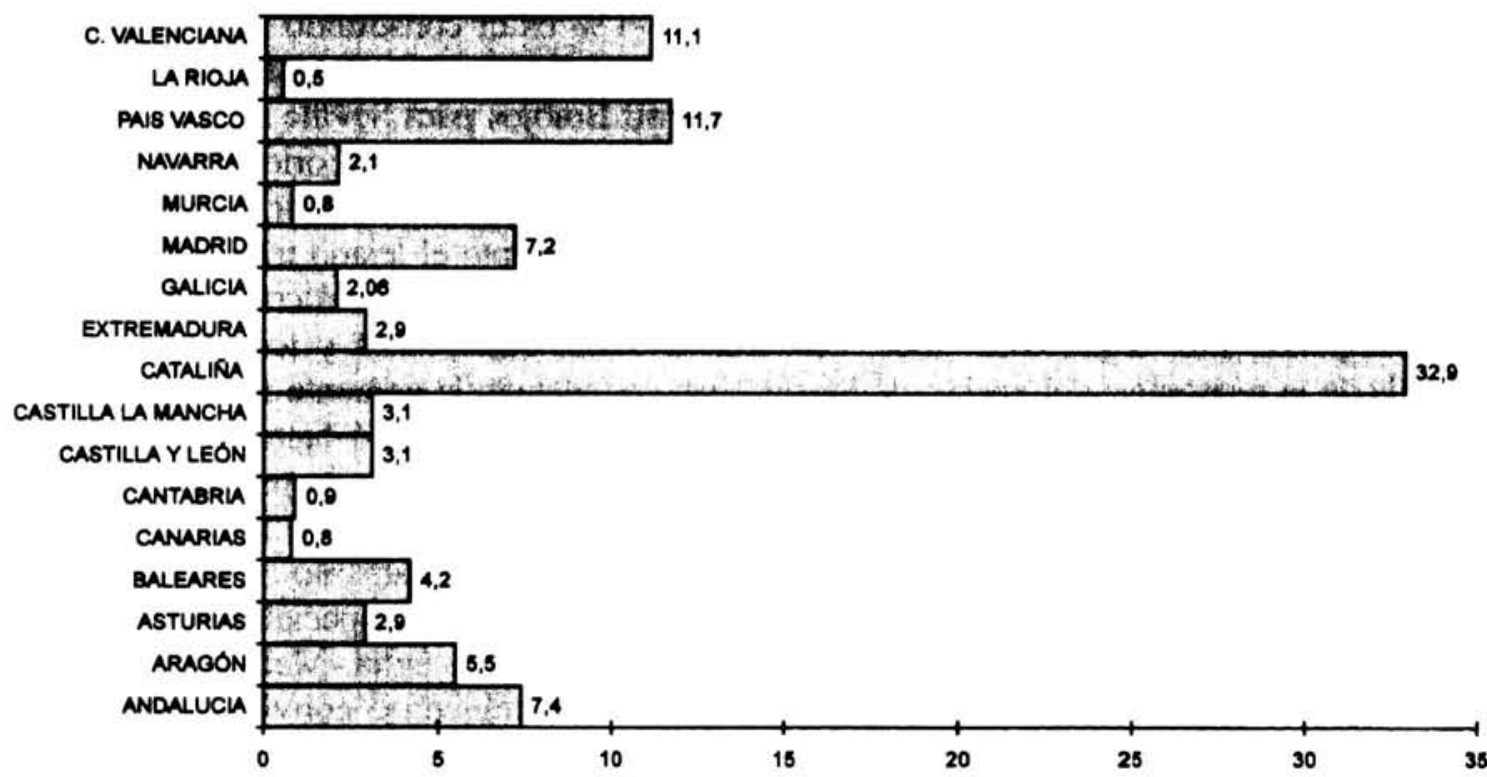

Fuente: «La Guerra civil (1936-1939)», en Bibliografias de Historia de España, n. ${ }^{7}$, Madrid, CINDOC (SCIC), 1996, 2 vols.

* Se recogen s6́lo aquellos documentos que incluyen topónimos (1308, $36 \%$ del total).

peración de la memoria histórica, especialmente evidente en esta región, que ha impulsado a numerosas corporaciones locales y editoriales -Edicions 62, L'Abadía de Montserrat- a financiar este tipo de investigaciones. A ello hay que sumar la presencia de grupos de trabajo entre los que destaca la altísima producción de autores como J. María Solé Sabaté y Joan Villarroya. Por provincias, Barcelona y Girona son las más estudiadas, seguidas por Lleida y Tarragona que en los últimos años se han acercado a los niveles de las dos primeras.

Cataluña está seguida de lejos por el País Vasco $(11,7 \%)$ y la Comunidad Valenciana $(11,1 \%)$. Para el País Vasco contamos con los trabajos pioneros de José María de Aguirre, Ricardo Miralles o Ángel Viñas, a los que años después se han unido, bajo los auspicios de Manuel Tuñón de Lara, autores como José Luis de la Granja, Carmelo Garitaonaindía o Manuel González Portilla. La incidencia ha sido mayor en Vizcaya, por la importancia de las operaciones en el Frente del Norte en esta provincia. Una quinta parte de los trabajos sobre esta región, en concreto una treintena de documentos, tiene como topónimo primordial Guernica, lo que nos indica el valor simbólico de tan controvertido acontecimiento. Merece la pena recordar la numerosa presencia de líderes del PNV como autores destacados.

La Comunidad Valenciana ocupa el tercer lugar entre las regiones más estudiadas (36). Su permanencia en zona republicana y la capitalidad de Valencia han influido decisivamente en que muchos trabajos se centren en ella. Los trabajos de Albert Girona, José Daniel Simeón o Vicente Gabarda para Valencia y de Glicerio Sánchez Recio y su grupo de colaboradores para Alicante tienen bastante que ver en estos niveles de producción. A este hecho debemos unir el alto número de revistas 
locales - Afers, Canelobre, Ullal-y universitarias - Anales de la Universidad de Alicante y Estudis d'Historia del País Valenciá-. Por último, hay que resaltar que Castellon es la provincia menos estudiada de las tres.

Un tercer grupo con producción entre el 7 y el $4 \%$ es el constituido por Andalucía, Madrid, Aragón y Baleares. Los trabajos de Francisco Moreno para Córdoba, Antonio Nadal para Málaga o Leandro Álvarez Rey y Alfonso Braojos para Sevilla han ido teniendo su continuidad en otras provincias menos estudiadas en los extremos oriental y occidental de la comunidad. Así las cosas, Andalucía sigue representando un importante campo de expansión en este ámbito. En la Comunidad de Madrid, excepto el lejano trabajo de Matilde Vázquez y Javier Valero, los estudios han tenido un claro matiz político y más escasamente regional. Los órganos de gobierno como la Junta de Defensa y toda la literatura derivada de la resistencia del pueblo de Madrid han completado la vertiente regional de este panorama. La importancia de Aragón radica en su papel estratégico - batallas del Ebro y Teruel- y por el recurrente tema de las colectivizaciones. Huesca es la provincia menos estudiada, mientras que los trabajos de Julián Casanova, Julia Cifuentes o Pilar Maluenda sobre Zaragoza vienen constituyendo un conjunto importante. Baleares no se puede entender sin la continua presencia en libros y revistas de Josep Massot -especialmente en Randa-, que ha sido uno de los autores más productivos sobre el tema. Mallorca, lugar de paso de la CTV italiana y punto de referencia en el Mediterráneo, se convierte así en una región especialmente bien estudiada en cuanto a la guerra civil se refiere (37).

Entre el $1 \%$ y el $3 \%$ contamos con los trabajos sobre Asturias, Castilla y León (38), Castilla-La Mancha y Extremadura mientras que Galicia y Navarra se sitúan en torno al 2\%. En Asturias predominan los estudios sobre represión, mientras que en Castilla y León van consolidándose estudios locales a un ritmo lento, vinculados cada vez más a explicar las bases sociales del régimen y la organización política de los sublevados en Salamanca y Burgos. Castilla-La Mancha cuenta con trabajos que se deben relacionar con Albacete como centro operativo de las Brigadas Internacionales y con Toledo por la cuestión del Alcázar. En Extremadura la progresión a partir del desarrollo de la Universidad ha compensado la presencia de estudios sobre Cáceres y Badajoz, centros vitales del desarrollo de los primeros meses de la guerra. Con respecto a Galicia, destacan los trabajos de Carlos Fernández Santander sobre las reacciones provocadas por la sublevación, a lo que debemos unir el impulso que Edicios do Castro ha dado a los estudios gallegos. En Navarra la base temática radica en el papel del general Emilio Mola y de los combatientes carlistas. Las regiones menos estudiadas, por debajo del $1 \%$, son La Rioja, Murcia, Cantabria, Tenerife y Las Palmas.

Finalmente, hay que señalar que uno de los temas regionalmente más estudiados es el de la represión. Es éste un tema que ha estimulado a numerosos investigadores y que cuenta con un soporte documental importante. Conviene insistir en la importancia de los factores de carácter institucional en el desigual desarrollo de la historia regional y local.

\subsection{Distribución cronológica}

A lo largo de los veinte años de producción historiográfica que nos ocupan, observamos las oscilaciones producidas en lo que se refiere a la distribución cronológica de los documentos.

Como muestra la figura 2, la producción sobre la guerra civil es bastante regular a lo largo del período de estudio. Estas leves variaciones se justifican por ser uno de los 


\section{Figura 2}

Distribución cronológica (núm. total de docs.)

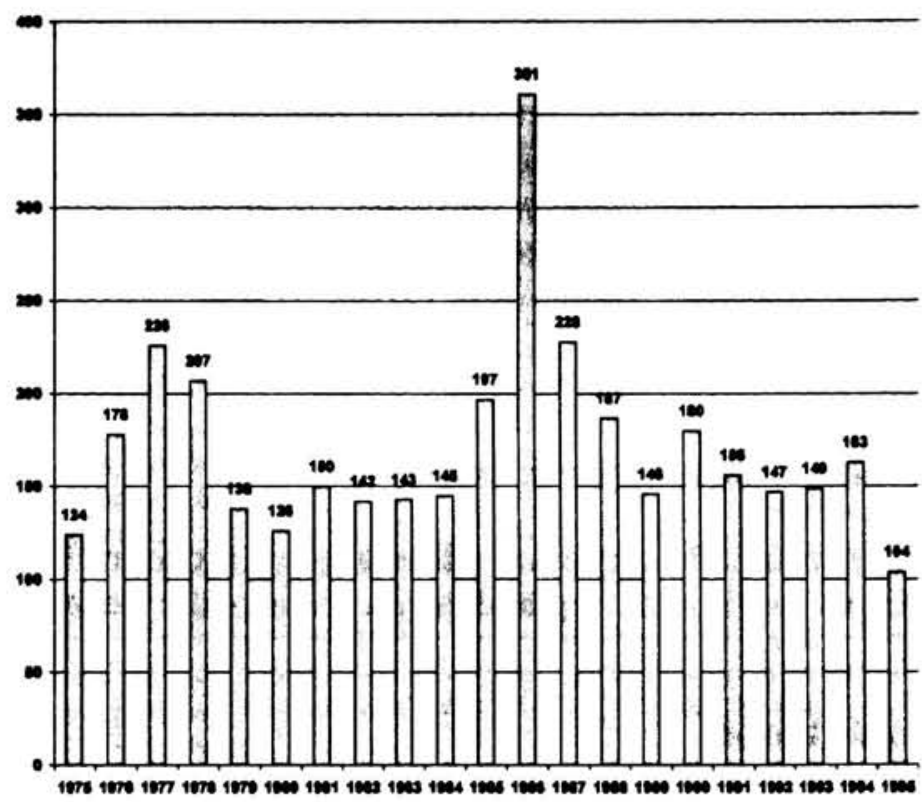

Fuente: «La Guerra civil (1936-1939)», en Bibliografias de Historia de España, n. 7, Madrid, CINDOC (SCIC), 1996, 2 vols.

temas de mayor producción historiografica, con un gran interés para un amplio perfil de investigadores - politólogos, sociólogos, periodistas y militares- así como para las editoriales. Como observamos en la figura 2, el grueso principal de la investigación se concentra en los años 80 , con un total de 1.745 documentos, y más concretamente en los años próximos a la celebración del cincuentenario (1986: 361 documentos y 1987: 228). La concentración bibliográfica en esa década se debe a múltiples factores. En primer lugar, la celebración de encuentros y coloquios con motivo del cincuentenario -Historia y Memoria de la guerra civil (Salamanca) o Socialismo y Guerra civil (Madrid) - estimula la producción historiográfica. A los mismos se suman los libros y números monográficos de revistas publicados. Respecto a estos últimos, se concentran entre 1986 y 1990. En segundo lugar, es un momento en el que asistimos a la creación de un gran número de revistas específicas de historia, tanto de ámbito nacional - Espacio, Tiempo y Forma, Aportes - como local -Afers, Canelobre, Alba, entre otras. Por otra parte, y en lo que se refiere a cuestiones más historiograficas, hay que señalar que es a partir de finales de los años 70 y principios de los 80 cuando comienza a conocerse más documentación sobre la guerra, al abrirse secciones de archivo que facilitan la tarea a los investigadores y posibilitan estudios más innovadores.

Respecto a las otras dos décadas, presentan un volumen considerable teniendo en cuenta que sólo se recogen cinco años (1975-80, 1990-95). En los 70, caracterizados por la transición política española, son años de reedición de obras escritas y editadas en la clandestinidad. Además, es la época en la que aparecen los trabajos de buena parte de los hispanistas franceses y británicos. Dada la escasez de revistas científicas, los investigadores del tema ofrecen parte de sus investigaciones a publicaciones 
de carácter más divulgativo, como es el caso de Historia 16, Tiempo de Historia e Historia y Vida.

La década de los noventa se presenta con un volumen considerable de publicaciones, teniendo en cuenta además que el bajo porcentaje de documentos de 1995 se debe al retraso en la actualización de bases de datos y catálogos existentes, así como la recepción de un buen número de revistas, en bibliotecas y centros de documentación. A la luz de los datos es evidente que existe un interés y, por tanto, una línea ascendente en cuanto a la producción a partir de los últimos años y de ahora en adelante. Todo hace pensar que el Sesenta aniversario sirva de estímulo a los investigadores interesados por el tema y se cierre la década con un saldo igual o superior a la de los años ochenta.

\subsection{Distribución por editoriales y revistas}

Resulta complicado unir los criterios editoriales en monografías y revistas, por lo que hemos optado por analizarlos separadamente para poder hacerlo con más detalle.

\subsubsection{Producción de libros}

Sobre los datos con que contamos debe ser realizada una separación previa entre la producción nacional y la internacional. Un $85 \%$ de los libros están publicados por editoriales nacionales, mientras que el $15 \%$ lo están por instituciones editoriales internacionales. Dentro del número de referencias con el que se ha trabajado, no resulta nada desdeñable la cifra de 300 libros extranjeros recopilados.

\section{La producción nacional}

Tal y como muestra la tabla II, un $82 \%$ procede del ámbito privado, mientras que un $16 \%$ tiene un origen público. Esta proporción no tiene parangón alguno en la producción historiográfica sobre historia española, cuestión ésta comprensible por la importancia y simbolismo de la guerra civil. El proceso de concentración editorial que vive nuestro país ha complicado la cuantificación de este tema pero salen a la luz algunos aspectos destacables. Madrid y Barcelona son sede de la mayoría de las editoriales, y un considerable número de editoriales se ha centrado en este tema en forma de series o colecciones. Así, en Barcelona, la serie Espejo de España de Planeta, centrada en biografías y memorias de un marcado cariz divulgativo o editoriales como Edicions 62 o L'Abadía de Montserrat centradas en aspectos regionales del conflicto. Mención especial merece la profundidad de estudios monográficos que han partido de editoriales de marcado sesgo historiográfico como Crítica o Grijalbo. Si hablamos de Madrid, aparece ante nosotros un panorama similar al de Barcelona, con excepción de los temas regionales. La divulgación ha corrido a cargo de empresas como Historia 16 o Júcar; el memorialismo en editores como Gregorio del Toro; la divulgación de los aspectos militares de la guerra por parte de la librería San Martín es muy destacada y las monografías de Siglo XXI, Akal o Alianza, que presentan publicaciones más especializadas. No debería ser imprescindible esta separación entre Madrid y Barcelona, 


\section{Tabla II}

Procedencia editorial de los libros sobre la guerra civil (1975-1995)

\begin{tabular}{|l|r|c|}
\hline \multicolumn{1}{|c|}{ Tipo editorial } & Núm. docs. & \% sobre el total \\
\hline Privadas & 1.224 & 82,5 \\
Comerciales & 1107 & \\
Fundaciones & 9 & \\
Asociaciones & 14 & \\
Ediciones de autor & 94 & \\
Coediciones & 20 & 0,4 \\
Públicas & 239 & 16,1 \\
Centrales & 35 & \\
Académicas & 78 & \\
Autonómicas & 48 & \\
Provinciales & 38 & \\
Locales & 40 & 100 \\
\hline Totales & 1.483 & \\
\hline
\end{tabular}

Fuente: «La Guerra civil (1936-1939)», en Bibliograflas de Historia de España, n. ${ }^{\circ}$ 7, Madrid, CINDOC (CSIC), 1996, 2 vols.

pero consideramos que es necesaria. Los años del cincuentenario trajeron consigo el hecho de que bastantes instituciones, en solitario o en forma de coediciones, publicaran monografías o actas de congresos, en forma de libros colectivos, en muy variados lugares de nuestra geografía. De la misma manera estas ciudades se reparten la puesta en circulación de las novelas más conocidas sobre la guerra, coincidiendo con las casas más comerciales del panorama nacional.

Finalmente, hay que puntualizar sobre el complejo elenco constituido por las tesis doctorales que, recogidas en su mayor parte en la recopilación bibliográfica, luego se han puesto en circulación, de manera total o parcial, en forma de libros. Es difícil separar muchas veces una cosa de la otra, pero siempre que ha sido posible hemos citado ambas. Por otro lado está el tema de las reediciones de libros y memorias publicados en el exilio en su mayoría. Es ésta una cuestión que no ha de perderse de vista a la hora de analizar personajes o temas que han recuperado $\longrightarrow 0$ no- su vigencia o han sido de alguna manera rehabilitados por la memoria histórica.

En cuanto a la producción pública, como indica la tabla II, se ha procurado hacer una división del contingente en función del productor. De tal modo que cuando hablamos de «central» hablamos de ministerios que han dedicado parte de sus esfuerzos a interesarse por los fondos archivísticos con que contaban. Como es de imaginar, normalmente hablamos del Ministerio de Cultura, ya que en la recopilación optamos por eliminar la matización de direcciones generales ante la confusión que originaba. Al menos se puede decir que ha estado presente en algunos de los acontecimientos vinculados a la historiografía de la guerra civil.

De las instituciones académicas - mundo universitario, CSIC - proceden las tesis doctorales que han supuesto destacadas profundizaciones en el mundo historiográfico. Como se puede comprobar, es el número más elevado entre el sector público. A esto debemos unir la publicación de las actas de encuentros científicos, principalmente con motivo del cincuenta aniversario. 
Los ámbitos autonómico, provincial y local arrojan un número aproximadamente similar de publicaciones. En cuanto a la producción de las comunidades autónomas ha influido decisivamente el modelo administrativo de la Constitución de 1978, que ha provisto a las consejerfas de cultura de una capacidad de inversión que transcurre paralela a la recuperación de la memoria histórica desde estos postulados territoriales, tal y como veíamos a la hora de hablar de la producción regional y local.

En el caso de lo provincial, ciertamente venido a menos, solemos referimos a las diputaciones y sus instituciones culturales. No se puede entender este hecho sin mencionar los archivos provinciales como unidad temática y documental, aun más profunda en el caso de los ayuntamientos que han proporcionado a sus pueblos y villas una historia de la guerra civil. Este hecho ha sido muy significativo en Cataluña. Por ello hemos hablado del arraigo de la historia local, o mejor, territorial de la guerra civil española.

\section{La producción internacional}

En el caso extranjero, podemos afirmar que una de cada cuatro obras tiene su origen en una universidad, en el estudio de un investigador, casi siempre en forma de tesis doctorales. El interés internacional por nuestra guerra ha suscitado la concurrencia de numerosos hispanistas. Hugh Thomas, Stanley G. Payne, Gabriel Jackson e Ian Gibson, han investigado el conflicto, sobre todo en los años en que la situación política española no permitía un estudio crítico. Esto ha condicionado de manera importante la historiografía sobre la guerra hasta que muchos autores españoles han ido concretando aspectos que se intuían o destruyendo tópicos. Hay un interés por el tema de carácter ideológico, de escenario de ensayo de la II Guerra Mundial, y una visión del conflicto con la participación internacional, de última guerra romántica. Por estas cuestiones, una parte importante del mundo académico internacional, sobre todo de la Historia, el Arte y la Literatura, han hecho de la España de los años treinta su campo de estudio (39).

Algo más de un $40 \%$ se vincula al mundo anglosajón, cuyas redes de distribución hacen que se publiquen los libros al mismo tiempo en Gran Bretaña y Estados Unidos. La función del hispanismo británico en los años de la transición y la cuestión de las brigadas internacionales ayudan a explicar que cerca de la mitad de las obras tengan este origen anglosajon.

De Alemania e Italia contamos con un elevado número de obras que, además, como han demostrado Walter Bernecker e Ismael Saz, no sólo se refieren al asunto de la intervención y de la estrategia política de los gobiernos fascistas, sino también a la reacción popular, el apoyo a la República y el fenómeno del brigadismo (40-41).

El exilio y la tradicional emigración explican que desde los países iberoamericanos, tomados en su conjunto, se hayan producido obras desde la perspectiva del memorialismo. El tráfico de esos libros, entre la justificación y la explicación, supone un tema importante en la España del tardofranquismo y la transición, con un importante número de reediciones de viejas obras.

En Francia, la proximidad, la importancia de aquellos años en el desarrollo de la II Guerra Mundial y la inquietud intelectual que provoca entre los estudiosos del tema la reacción francesa ante nuestro conflicto, ha hecho que también sea un tema 
Tabla III

Producción internacional de libros

\begin{tabular}{|l|c|c|}
\hline \multicolumn{1}{|c|}{ Pats } & N. doc. & $\%$ \\
\hline P. anglosajones & 122 & 41,9 \\
Italia & 58 & 19,9 \\
P. iberoamericanos & 42 & 14,4 \\
Alemania & 41 & 14 \\
Francia & 31 & 10,6 \\
Unión Soviética & 17 & 5,8 \\
Otros & 18 & 6,1 \\
\hline Total & 291 & 100 \\
\hline
\end{tabular}

Fuente: «La Guerra civil (1936-1939)», en Bibliografías de Historia de España, n. 7 , Madrid, CINDOC (CSIC), 1996, 2 vols.

recurrente, favorecido por más de un encuentro científico entre historiadores de ambos países (42). A estos factores debemos añadir la presencia de buena parte del exilio republicano en territorio francés. A pesar de la distancia y del tiempo, existe una historiografía rusa que ha hecho hincapié en varios asuntos controvertidos de la participación soviética y de las relaciones entre el gobierno republicano y la Tercera Internacional (15).

Finalmente, y en virtud de la difusión del fenómeno brigadista, se cuenta con varios estudios y libros de memorias de países tan lejanos como Japón o Finlandia, por poner algún ejemplo.

\subsubsection{Producción de revistas}

Como ya señalábamos, la guerra civil española ha sido investigada por distintos colectivos profesionales, por lo que no es de extrañar la dispersión existente en el tipo de revistas que abordan el tema. Si bien el grueso principal se centra en revistas de historia, universitarias y regionales fundamentalmente, también encontramos interesantes estudios en revistas de literatura o economía. En un total de 447 revistas -218 extranjeras y 229 españolas - se recogen los 1.749 artículos recopilados.

Aplicando la ley de la dispersión de la ciencia o ley de Bradford (43), observamos cómo en este caso se cumplen sus principios, ya que la mayoría de los artículos sobre la guerra se concentra en un número reducido de revistas -878 documentos en 24 revistas-, y el resto en una serie más amplia de ellas, muchas de las mismas sin conexión directa con la disciplina. Cabe señalar que esta ley se cumple particularmente en el caso de las revistas extranjeras, ya que la mayoría de ellas recoge en estos veinte años de producción, salvo las más prolíficas, de uno a tres trabajos. Este hecho supone, como es evidente, una dificultad añadida a la hora de recuperar de forma exhaustiva la producción historiográfica sobre este tema.

Dadas las diferencias - normalización, periodicidad, etc.- existentes entre las revistas españolas y extranjeras, hemos considerado su estudio por separado para un 
mayor conocimiento de las mismas. En la tabla IV se presentan las revistas españolas que, entre las 229 recogidas, han publicado más de 20 trabajos, estableciendo este número como significativo para su evaluación.

Tabla IV

Revistas españolas más productivas

\begin{tabular}{|l|c|c|c|}
\hline \multicolumn{1}{|c|}{ Revistas } & $N^{\circ}$ documentos & Fecha incio-final & Periodicidad \\
\hline Historia y Vida & 181 & $1968-$ & Mensual \\
Historia 16 & 156 & $1976-$ & Mensual \\
Tiempo de historia & 69 & $1974-1982$ & Mensual \\
L' Avenc & 59 & $1976-$ & Mensual \\
Aportes & 23 & $1986-$ & Cuatrimestral \\
Cuenta y Razón & 23 & $1981-$ & Bimestral \\
Espacio, Tiempo y Forma & 23 & $1989-$ & Anual \\
Revista de Girona & 21 & $1955-$ & Bimestral \\
Anthropos & 20 & $1987-$ & Mensual \\
Randa & 20 & $1975-$ & Bimestral \\
\hline
\end{tabular}

Fuente: «La guerra civil (1936-1939)», en Bibliografías de Historia de España, n. ${ }^{\circ} 7$. Madrid, CINDOC (CSIC), 1996, 2 vols.

La mayoría de ellas - salvo Anthropos y Cuenta y Razón- son específicas de historia; despuntando entre las mismas Historia y Vida e Historia 16 con más de cien artículos, y siguiéndolas con más de cincuenta, Tiempo de Historia y L'Avenc. Estas revistas, de divulgación hacia el gran público, cuentan con varias ventajas; son editadas por empresas comerciales, tienen un período de vida más largo - salvo Tiempo de Historia que se dejó de publicar en 1982-, y tienen una periodicidad mensual y, por tanto, un mayor volumen de trabajos/año. Existe una tendencia a eliminar estas publicaciones en este tipo de estudios por su carácter divulgativo y menos científico, sin embargo en ellas y fundamentalmente en los años setenta y principios de los ochenta en que el número de revistas específicas de historia era muy bajo, publicaban los autores más considerados científicamente a la vez que los extranjeros, como es el caso de Herbert R. Southworth, Hugh Thomas o Michael Alpert. A destacar es el caso de la revista Espacio, Tiempo y Forma, que con seis años de vida y una periodicidad anual ha publicado un total de veintitrés trabajos. A las revistas «más productivas» les siguen otras que con una vida más corta - se crearon a mediados/finales de los 80 y una periodicidad que oscila entre cuatrimestral y semestral-, han recogido un número considerable de trabajos sobre la guerra. Es el caso, principalmente, de Anales de Historia Contemporánea, Afers, Anales de la Universidad de Alicante, Canelobre y Estudis d'Historia del País Valenciá.

Analizando la procedencia editorial de la totalidad de las revistas españolas recogidas en nuestro estudio - véase tabla $\mathrm{V}$ - observamos que principalmente es el sector público $(37,5 \%)-y$ dentro del mismo las instituciones académicas $(29,6 \%)$ con las universidades a la cabeza $(23,6 \%)$ - el que concentra la producción editorial. Porcentaje no muy inferior alcanzan las instituciones privadas $(34,9 \%)$, por lo que podemos señalar que es un tema que interesa tanto al mundo académico e insti- 


\section{Tabla V}

Análisis por instituciones editoras españolas

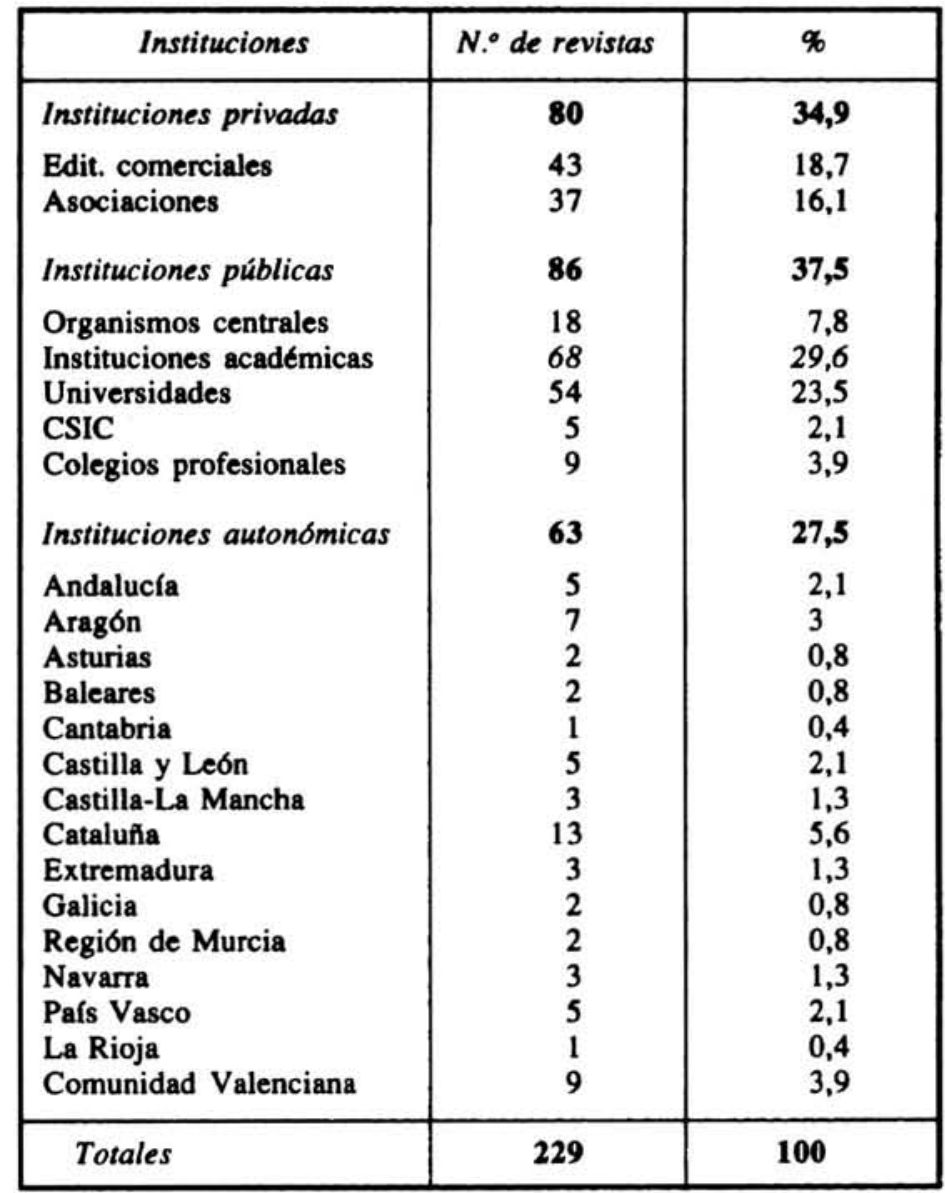

Fuente: «La Guerra civil (1936-1939)», en Bibliografias de Historia de España, n. ${ }^{\circ}$, Madrid, CINDOC (CSIC), 1996, 2 vols.

tucional como al del editor privado. Cabe destacar al respecto la importancia del mundo editorial catalán, siendo un ejemplo ediciones Curial.

En lo que se refiere a las instituciones autonómicas $(27,5 \%)$-ayuntamientos, diputaciones y asociaciones-, observamos la presencia de la casi totalidad de las regiones, aunque sea con valores muy bajos, lo que corrobora lo que ya señalábamos; el interés regional y local del tema. Entre las regiones recogidas destaca Cataluña con un $5,6 \%$, seguida por la Comunidad Valenciana con un $3,9 \%$.

Por lo que se refiere a las revistas extranjeras, hay que destacar dos aspectos fundamentales: su elevado número y su diversidad geográfica. El primer aspecto se explica por la proyección internacional del tema y el interés despertado entre distintos colectivos. En cuanto a su amplitud geográfica - 31 países - sorprende encontrarse artículos sobre la guerra en publicaciones editadas en países muy distantes geográfica y culturalmente de España. Son países que no tuvieron relación directa con el conflicto, si bien se justifica, en parte, por la participación de brigadistas de los más diversos países, como es el caso de Australia, República Centroafricana o la India. Los 
países que concentran el mayor número de publicaciones son: Estados Unidos (47), Gran Bretaña (35), Francia (26), Italia (20) y Alemania (13). En el caso americano, la dispersión de publicaciones es muy acusada mientras que las revistas más productivas se concentran en Italia y el Reino Unido. Les siguen muy de cerca otros países como Polonia y Australia (8 y 7 trabajos respectivamente); Unión Soviética, Rumanía, Canadá y Yugoslavia (6); Argentina, Hungría y Bélgica (4); Cuba (3); y en menor medida: México, Bulgaria, Holanda, Suiza, Japón y Dinamarca (2); Nueva Zelanda, República Centroafricana, Austria, Colombia, Túnez, India, Turquía, Suecia, Checoslovaquia y Noruega, con una revista.

La dispersión en las revistas extranjeras es mucho más elevada que en las españolas. De los 218 títulos, seis publicaciones recogen más de diez trabajos — véase tabla VI- estableciéndose este número como significativo para su evaluación. De entre las más "productivas» cabe destacar a Spagna Contemporanea que con cuatro años de vida y ocho números publicados ha dedicado once estudios a la guerra española. A las revistas «más productivas», las siguen otros títulos como la soviética Novaya y Novashaya Istoria (9 documentos) o la inglesa Journal of Contemporary History (7). Temáticamente han abordado, principalmente, la intervención y proyección internacional de la guerra, así como aspectos militares de la misma.

\section{Tabla VI}

Revistas extranjeras más productivas

\begin{tabular}{|l|c|}
\hline \multicolumn{1}{|c|}{ Revistas } & N.o de documentos \\
\hline Belgisch Tijdschrift voor Nieuwste Geschiedenis & 16 \\
European History Quarterly & 14 \\
Militargeschichte & 13 \\
Bulletin d'Information Fiehs & 11 \\
Spagna Contemporanea & 11 \\
Italia Contemporanea & 10 \\
\hline
\end{tabular}

Fuente: «La Guerra civil (1936-1939)», en Bibliografias de Historia de España, n. ${ }^{7}$, Madrid, CINDOC (CSIC), 1996, 2 vols.

Analizando la procedencia editorial de las revistas extranjeras observamos cómo, a diferencia del caso español, se concentra en editoriales y asociaciones privadas ocupando prácticamente el $70 \%$ del total, mientras que el resto son fundaciones, instituciones y universidades públicas. Entre los editores privados cabe destacar a Jandhondt, de la revista Belgisch Tijdshrift voor Nieuwste Geschiedenis, y entre las universitarias a la Universidad de Burdeos, Bulletin Hispanique, o a la de Bologna, editora de Cristianesimo nella Historia.

\subsection{Productividad por autores}

Dadas las características específicas del tema y su proximidad cronológica, la guerra civil española no ha sido solamente investigada por historiadores. A ella se han acercado periodistas, politólogos, pedagogos y militares, entre otros colectivos, 
intentando desentrañar, desde el punto de vista de su especialidad, aspectos de interés. Los estudios de productividad por autores han sido investigados por Lotka (44) y dan como resultado, como se demuestra en nuestro estudio, la existencia de un pequeño grupo de personas muy productivas al lado de un gran número que apenas publican. Con un total de 2.277 autores en nuestra bibliografía, sólo 24 han publicado más de diez trabajos, estableciendo este número como significativo para analizar la producción historiográfica sobre la guerra civil española.

Antes de abordar más detalladamente algunos aspectos de los autores más prolíficos, nos gustaría hacer algunas matizaciones al respecto que escapan de la mera cuantificación matemática. En primer lugar, que «cantidad» no significa «calidad», ya que son múltiples los factores que influyen a la hora de publicar trabajos de investigación, pues si bien el prestigio y la consideración es siempre un aval, en ocasiones las políticas editoriales, la pertenencia a consejos de redacción, así como los «colegios invisibles», influyen en la aceptación o no de determinados trabajos. Factores políticos o sociales pueden influir, además, en la alta o baja producción de los autores según las épocas. En segundo lugar, conviene diferenciar el tipo de publicación, pues aunque la calidad científica del trabajo no está asegurada siempre, la envergadura de la publicación de un libro no es comparable a la de un artículo de revista. Con ello no queremos caer en el tópico, tan extendido desgraciadamente en nuestro país, de primar la publicación en libros, ni mucho menos; creemos que los trabajos recogidos en revistas son muchas veces de un alto valor científico, comparable al de los libros, además de ser una vía rápida y accesible para la difusión de la literatura científica.

Realizadas estas puntualizaciones, hemos ordenado a modo de ranking a los veinticuatro investigadores que han publicado más de diez trabajos, como observamos en la tabla VII. Entre ellos es evidente que no todos tienen la misma consideración científica y sus trabajos no cuentan con el mismo valor historiográfico. También pueden echarse en falta algunos nombres clave en la investigación histórica sobre la guerra civil que, con un número no muy inferior al de los más prolíficos; han realizado aportaciones significativas. Adentrándonos ya en el análisis de los autores más productivos, nos centraremos en sus líneas de investigación, las editoriales y revistas en las que publican, si lo hacen o no a nivel internacional y en qué años se concentra su producción bibliográfica.

José Luis Infiesta Pérez (bajo el seudónimo en los años 70 y 80 de José Luis Alcofar Nassaes) se presenta como el autor más prolífico de nuestro estudio con un total de 37 trabajos, principalmente publicados en revistas - Historia 16, Historia y Vida, Revista de Historia Militar, entre otras- y cuya temática se centra en aspectos militares del conflicto, publicando desde la década de los setenta hasta la actualidad. José Manuel Martínez Bande aborda el ámbito militar desde los años setenta, publicando en la editorial San Martín principalmente. Por su parte, Josep Massot Muntaner ha centrado su investigación en aspectos muy concretos del ámbito balear, tales como la represión llevada a cabo por las tropas franquistas al tomar las islas o las biografías de personajes implicados en esa zona. Sus trabajos se condensan fundamentalmente en los años 70 y 80 y mientras su publicación en revistas se diversifica mucho - Randa, Afers, Historia 16, Studia Monástica, etc.- sus libros se han editados por L'Abadía de Montserrat. Julio Aróstegui ha abordado fundamentalmente aspectos referidos a los combatientes carlistas, así como balances sobre la Repú- 
Tabla VII

Productividad por autores

\begin{tabular}{|l|r|r|c|}
\hline Autores & Libros & Arts. revista & Total doc. \\
\hline J. L. Infiesta Perez & 3 & 34 & 37 \\
J. M. Martínez Bande & 20 & 6 & 26 \\
J. Massot Muntaner & 9 & 16 & 25 \\
J. Aróstegui Sánchez & 5 & 13 & 18 \\
H. Raguer Sunyer & 5 & 11 & 16 \\
M. Tuñón de Lara & 7 & 9 & 16 \\
A. Viñas Martín & 5 & 11 & 16 \\
J. Villarroya y Font & 7 & 8 & 15 \\
M. Alpert & 3 & 11 & 14 \\
R. Salas Larraź́bal & 4 & 10 & 14 \\
J. Tusell Gómez & 5 & 9 & 14 \\
J. M. Sole Sabaté & 7 & 6 & 13 \\
W. L. Bernecker & 6 & 6 & 12 \\
G. Cardona Escanero & 3 & 9 & 12 \\
A. Bosch Sánchez & 6 & 5 & 11 \\
J. Clara Resplandis & 1 & 10 & 11 \\
A. Girona Albuixech & 1 & 10 & 11 \\
J. L. de la Granja Sáinz & 4 & 7 & 11 \\
M. T. Suero Roca & 1 & 10 & 11 \\
A. Álvarez Bolado & 0 & 10 & 10 \\
S. Álvarez Gómez & 6 & 4 & 10 \\
R. Fraser & 5 & 5 & 10 \\
J. García Durán & 1 & 9 & 10 \\
J. M. Gárate Córdoba & 4 & 6 & 10 \\
\hline
\end{tabular}

Fuente: «La Guerra civil (1936-1939)», en Bibliografias de Historia de España, n. ${ }^{\circ}$, Madrid, CINDOC (CSIC), 1996, 2 vols.

blica y la guerra o la producción historiográfica sobre esta última. Sus trabajos se condensan en los años 80 y 90, diversificándose en cuanto a las revistas en las que publica, desde universitarias como Historia Contemporánea, a locales como Canelobre, entre otras. Es el autor que más participa en los números monográficos que las revistas han dedicado a la guerra, lo que junto a su colaboración en obras de recopilación sobre distintos aspectos de la guerra supone una nota de reconocimiento para el autor. Por su parte, Hilari Raguer Sunyer ha estudiado principalmente los aspectos religiosos de la guerra así como la postura del Vaticano ante la misma. Sus trabajos abarcan desde los años 70 hasta la actualidad, destacando por la publicación en revistas extranjeras - Cristianesimo nella Storia y Revue d'Histoire Ecclesiastiquemientras en las españolas concentra su producción en Historia y Vida e Historia 16, fundamentalmente; a su vez sus libros son publicados por L'Abadía de Montserrat.

En lo que se refiere a Manuel Tuñón de Lara, su prestigio académico le hace participar en obras recopilatorias en las que aborda diversos temas del conflicto bélico; aspectos militares, internacionales, la no-intervención, entre otros. Sus trabajos publicados en revistas se diversifican en distintos títulos, resaltando además su colaboración en una revista rumana (45). Angel Viñas dirige su investigación desde los años 70 en dos líneas temáticas principalmente: los aspectos internacionales del conflicto, y los económicos referidos al oro del Banco de España. Sus trabajos publicados en revistas se concentran principalmente en Historia 16 y es uno de los pocos 
autores españoles con artículos publicados en revistas extranjeras (46). Joan Villarroya y Font es coautor de varios trabajos con Solé Sabaté, y de algunos personales, analizando aspectos políticos, principalmente la represión en Cataluña. Sus trabajos se recogen en editoriales y publicaciones catalanas, véase: L'Abadía de Montserrat, Recerques y L'Avenc, entre otras.

Por su parte, Michael Alpert se ha centrado fundamentalmente en la postura inglesa ante el conflicto español así como en los aspectos militares de la guerra. Sus estudios se localizan desde los años 70 hasta la actualidad, diversificándose en revistas nacionales - Historia y Vida, Historia 16- e internacionales - History Today, European History Quarterly—; sus publicaciones en libros están recogidas principalmente por la editorial Siglo XXI. Ramón Salas Larrazábal, especialista en historia militar, ha tratado, además de algunos aspectos bélicos del conflicto, de la represión; su producción abarca desde los años 70 hasta su fallecimiento en los 90 y su publicación en revistas no se centra sólo en las específicas de historia militar. Javier Tusell ha colaborado desde los años ochenta en obras recopilatorias abordando distintos aspectos del conflicto, principalmente de carácter político. Sus trabajos en revistas se diversifican en distintos títulos que van desde Espacio, Tiempo y Forma a Cuenta y Razón o Historia 16.

La historia social de la guerra ha sido analizada, junto a los aspectos internacionales del conflicto, por el investigador alemán Walter Bernecker. Encontramos trabajos suyos publicados indistintamente en editoriales y revistas españolas y extranjeras desde los años 70 hasta la actualidad. En lo que se refiere a Gabriel Cardona, sus estudios sobre aspectos militares de la guerra son clave en la historiografía española desde los años setenta. Cabe destacar sus trabajos en obras colectivas como la de Historia 16.

Los aspectos políticos y sociales de la guerra en el ámbito valenciano han sido investigados por Aurora Bosch, estudiando las colectivizaciones, la reforma agraria y los partidos de izquierda principalmente; su producción abarca desde la década de los 80 hasta la actualidad.

Por su parte, Josep Clara investiga diversos aspectos de la guerra en otro ámbito geográfico, Girona y su provincia; cronológicamente sus trabajos se concentran en los años 80 y en revistas catalanas: L'Avenc y Revista de Girona. El ámbito de la Comunidad Valenciana es analizado también por Albert Girona de forma más general que Aurora Bosch, profundizando en aspectos historiográficos, políticos y economicos de dicha región. Su producción se centra en los años 80 en revistas locales fundamentalmente, como Ullal y Estudis d'Historia Contemporánea del País Valenciá. José Luis de la Granja ha realizado importantes balances historiográficos en colaboración con Ricardo Miralles y Santiago de Pablo, a la vez que ha tratado también fuentes de archivo. A ello se suman sus investigaciones sobre aspectos políticos del País Vasco. Sus publicaciones aparecen en distintas editoriales y revistas desde los años 80. M. ${ }^{\star}$ Teresa Suero Roca se ha preocupado por ahondar en la biografía de algunos de los protagonistas de la guerra, principalmente militares, como fueron el general Núñez de Prado y el coronel Escobar, entre otros. Cronológicamente sus trabajos se sitúan desde los años 70 hasta la actualidad, publicando en revistas españolas. En lo que se refiere a Alfonso Álvarez Bolado cabe señalar que sus trabajos, referidos a aspectos religiosos de la guerra, se concentran en los años 80 y principios de los 90 en dos revistas, Razón y Fe y Miscelánea Comillas, mientras que San- 
tiago Alvárez ha tratado aspectos políticos de la guerra muy relacionados con el bando republicano. Por su parte, Ronald Fraser se ha centrado en la historia oral de la guerra así como en estudios generales de la misma, publicando desde los años 70 en editoriales y revistas españolas y extranjeras. Señalemos igualmente los trabajos realizados por Juan García Durán sobre fuentes históricas y sobre aspectos internacionales de la guerra. Sus trabajos están recogidos mayoritariamente en revistas desde la década de los setenta. Para finalizar, hay que resaltar los estudios de José M. Garate Córdoba quien ahonda en aspectos militares de la guerra desde los años 70.

Respecto a los autores extranjeros que han investigado el tema, si bien no cuentan con el volumen de publicaciones que los autores más "productivos», algunos de ellos han realizado importantes aportaciones temáticas y metodológicas a la investigación histórica sobre la guerra. Tal es el caso de Luigi Paselli, Tom Buchanan o Marklen T. Mescheriakov.

Otro aspecto interesante a destacar es la publicación de trabajos de autores españoles en revistas y editoriales extranjeras y viceversa. Mientras la primera es bastante baja, la segunda se caracteriza tanto por su alto porcentaje como por su diversidad geográfica. Los autores españoles optan principalmente por publicaciones anglosajonas, francesas e italianas. Temáticamente podemos decir que los aspectos sobre los que tratan se circunscriben a los de política interior así como a la proyección internacional del conflicto. En lo que se refiere a los trabajos de autores extranjeros en publicaciones españolas, cabe destacar varios aspectos: númericamente su participación es elevada, temáticamente abordan principalmente la intervención extranjera, si bien también analizan aspectos políticos y económicos del conflicto, descuidando los sociales y culturales; cronológicamente publican desde los años 70 y geográficamente el abanico se diversifica desde el mundo anglosajón, con Hugh Thomas a la cabeza, hasta el japonés con los estudios económicos de Yasuhiro Fukasawa.

\section{Conclusiones}

Este análisis, por las razones que hemos ido indicando, nos permite extraer unas conclusiones significativas. Estudios de este tipo nos acercan a la historiografía de la guerra civil de forma más próxima que las disertaciones ya realizadas sin apoyo documental alguno. Creemos que nuestro trabajo puede dar pie a multitud de estudios bibliométricos que se centren en algún aspecto concreto de los que aquí hemos analizado: estudio de citas, niveles de impacto, etc.

- La importancia cuantitativa y cualitativa de la investigación sobre la guerra civil en publicaciones españolas y extranjeras. Dentro de esto destaca la gran variedad de autores que se han acercado al tema, desde todas las posiciones y criterios, y el alto interés de los historiadores extranjeros.

- La descompensación historiográfica en cuanto a los aspectos tratados, así como el estudio de las zonas en litigio, siendo más numerosos en todos los aspectos los realizados sobre la zona republicana.

- El desequilibrio regional entre las distintas comunidades estudiadas, destacando los estudios sobre Cataluña, País Vasco y Comunidad Valenciana. 
- La concentración cronológica en la década de los ochenta, principalmente en los años de celebración del cincuentenario, y en los de la transición política española, si bien se prevé que el balance de los 90 llegue a ser tan cuantioso dado el interés por el tema en la historiografía actual.

- Respecto a los trabajos publicados en revistas cabe señalar la dispersión existente, así como el alto porcentaje de números monográficos y la aceptación por revistas extranjeras. Finalmente el apoyo de instituciones públicas y privadas que financian las revistas que recogen dichos estudios, lo que indica el interés académico y divulgativo de la guerra civil española.

- En lo relativo a libros destaca la misma heterogeneidad que en las revistas. El desarrollo de la historia regional y local ha venido siendo bastante desequilibrado, si bien hay regiones que han aumentado su número de estudios en los últimos años. Son numerosos los libros colectivos cuyo rastro resulta más difícil de seguir.

Estas valoraciones, pues, son fruto como señalábamos al comienzo de nuestro estudio de una amplia y rigurosa bibliografía que recoge en 3.597 referencias lo publicado sobre la guerra civil española entre 1975 y 1995. Este esfuerzo lo daríamos por suficientemente recompensado si sirviera de herramienta útil a todos los investigadores interesados en el tema.

\section{Agradecimientos}

Queremos agradecer desde aquí el apoyo y asesoramiento prestado en la elaboración del n. 7 de la Serie BIHES. Bibliografías de Historia de España. La Guerra Civil (1936-1939), a la coordinadora de la Serie, María Cruz Rubio Liniers, y a los profesores Julio Aróstegui y Juan Andrés Blanco Rodríguez, colaboradores del número.

\section{Bibliografia}

1. BLANCO, J. A. Veinte años de historiografía de la guerra civil española, 1975-1995. Estudio historiográfico. BIHES. Bibliografias de Historia de España, La Guerra civil (1936-1939) n. 7, vol. 1 , pp. 1-78, 1996.

2. PRITCHARD, A. Statiscal bibliography or bibliometrics. Journal of Documentation 1969 , vol. 25 , n..$^{\circ}$, pp. 348-369.

3. ALCAIN, M.: D.; SAN MILlAN, M.: J. Uso y tendencias de las técnicas bibliométricas en ciencias sociales y humanas a nivel internacional. Revista Española de Documentación Científica, 1993, vol. 16, n. ${ }^{\circ} 1$, pp. 30-41.

4. ALMUIÑA, C. Hispania, Revista de Historia (1940-1989). Análisis y evolución de contenidos. Hispania, 1990, vol. 50/2, n. ${ }^{\circ} 175$, pp. 393-416.

5. PÉREZ HERRERO, P. La consolidación de la imagen de Hispanoamérica en la historiografía española (1935-1986). En: HUGUET, M., NIÑO, A.; PEREZ, P.: La formación de la imagen de América Latina en España. 1898-1989, 1992, Madrid: OEI, pp. 241-275.

6. ROMÁN ROMÁN, A. Las revistas de ciencias sociales, fuente para el estudio de la historia: la transición (1975-1985), una perspectiva historiográfica y documental. 1993, Madrid: Universidad Complutense. 
7. NIÑO, A.; SÁEZ, C.; SÁNCHEZ, R.; SANTI, M. Análisis bibliométrico de la investigación realizada en el Departamento de Historia Contemporánea. Cuadernos de Historia Contemporánea, 1994, n. ${ }^{\circ} 16$, pp. 185-204.

8. RUBIO LINIERS, M.' C.; RUIZ FRANCO, M.* del R. La investigación histórica sobre el franquismo: un análisis bibliométrico de las revistas españolas (1976-1992). Revista Española de Documentación Cientifica, 1994, vol. 17, n. ${ }^{\circ} 4$, pp. 413-426.

9. NƯNEZ, M." G. Bibliografía comentada sobre la II República Española (1942-1992), 1993, Madrid: FUE.

10. GARCIA DURÁN, J.: La guerra civil española. Fuentes, 1985, Barcelona: Crítica.

11. MESCHERIAKOV, M. T. Inspanskaya respublica y Komintern (Nationalno-Revolutionnaya ispanskogo naroda y politica kounistiches-Kogo internatsinala, 1936-1939 1981, Moscú: MYSL.

12. MESCHERIAKOV, M. T. Sovestskii soiuz y antifashistskaia voina ispanskogo naroda (1936-1939 GG). Istoriia SSSR, 1988, n. ${ }^{\circ}$, pp. 22-40.

13. GYORKEI, J. A spanyol szabadsagharc emlekere. Tarsadalmi Szemle, 1976, vol. 31, n. ${ }^{\circ}$ 7, pp. 39-43.

14. GYÓRKEI, J. A spanyolorszagi nemzetközi brigadok egészségügyi szolgalata. Hadtörténelmi Közlemények, 1986, vol. 33, n. ${ }^{\circ} 4$, pp. 740-750.

15. POZHARSKAYA, St. La historiografía soviética sobre la guerra civil española. En: ARÓSTEGUI, J. (coord.). Historia y memoria de la guerra civil, 1988, Valladolid: Junta de Castilla y León, vol. II, pp. 57-70.

16. VIÑAS, A.: La Alemania nazi y el 18 de julio. Antecedentes de la intervención alemana en la guerra civil española, 1977, Madrid: Alianza Universidad.

17. COVERDALE, J. F. Intervención fascista en la guerra civil española, 1979, Madrid: Alianza.

18. PAYNE, S. G. Falange. Historia del fascismo español, 1986, Madrid: Sarpe.

19. ELLWOOD, S. Prietas las filas: Historia de la Falange española (1933-1983), 1984, Barcelona: Crítica.

20. RUBIO, J. La emigración de la guerra civil de 1936-1939, 1977, Madrid: San Martín.

21. SOLÉ SABATÉ, J. M.; VILLARROYA, J. La repressió a la guerra y a la postguerra a la comarca del Maresme (1936-1945), 1983, Barcelona: Publicacions de L'Abadía de Montserrat.

22. SOLÉ SABATÉ, J. M.; VILLARROYA, J. La repressió a la reraguarda de Catalunya (1936-1939), 1990, Barcelona: Publicacions de L'Abadía de Montserrat.

23. NASH, M. Women in the Spanish Civil War, 1995, S.L.: Arden Press Incorporated.

24. DI FEBO, G. Resistencia y movimiento de mujeres en España (1936-1976), 1979, Barcelona: Icaria.

25. GIBSON, I. En busca de José Antonio, 1980, Barcelona: Planeta.

26. PASELLI, L. Azaña e la guerra di Spagna. Nuova Antologia, 1985, vol. 1, n. ${ }^{\circ} 2153$, pp.152-191, vol. 2 , n. ${ }^{\circ} 2155$, pp. 379-415 y vol. 3 , n. ${ }^{\circ} 2156$, pp. 367-408.

27. PRO RUIZ, J. Sobre el ámbito territorial de los estudios de Historia. Historia a Debate: Santiago, 1995, vol. 1, pp. 59-66.

28. ARÓSTEGUI, J.; BRICALL, J. M.", TUÑÓN DE LARA, M. et al. La guerra civil española. 50 años después, 1985, Barcelona: Lábor.

29. BROUÉ, P. La revolución española, 1931-1939, 1971, Barcelona: Península.

30. PRESTON, P. La guerra civil española (1936-1939), 1987, Barcelona: Plaza \& Janés.

31. THOMAS, H. La guerra civil española (1936-1939), 1995, Barcelona: Grijalbo.

32. SANTACREU SOLER, J. M. La historiografía de los aspectos económicos de la guerra civil española. Hispania, 1990, vol. 50, n. ${ }^{\circ} 176$, pp. 1405-1415.

33. VIÑAS, A. Dimensiones económicas e internacionales de la guerra civil: una presenta- 
ción de la literatura reciente. En: TUÑON DE LARA, M. et al. Historiografía española contemporánea, 1980, Madrid: Siglo XXI, pp. 355-379.

34. BOSCH, A. Colectividades anarquistas y guerra civil en el Pats Valenciano, 1980, Valencia: Ed. del Autor.

35. MONJÓ, A.; VEGA, C. Els traballadors y la guerra civil. Historia d'una industria catalana, 1986, Barcelona: Empuries.

36. GIRONA, A. La historiografia de la guerra civil en el país valenciano. Studia Histórica, Historia Contemporánea, 1985 , vol. 3, n. ${ }^{\circ} 4$, pp. 137-146.

37. GIRONA, A.; MORENO, F.; VILLARROYA, J. Estado actual de la bibliografía territorial sobre la guerra civil. En ARÓSTEGUI, J. (coord.). Historia y memoria de la guerra civil, 1988, Valladolid: Junta de Castilla y León, vol. 3, pp. 401-451.

38. BLANCO, J. A. Los estudios sobre la guerra civil en Castilla y León. Studia Zamorensia, 1995, vol. 2, pp. 125-141.

39. PAYNE, S. G. Recent historiography on the Spanish Republic and Civil War. Journal of Modern History, 1988, n. ${ }^{\circ}$ 60, pp. 541.

40. BERNECKER, W. L. La historiografía alemana sobre la guerra civil española. En ARÓSTEGUI, J. (coord.), Historia y memoria de la guerra civil, 1988, Valladolid: Junta de Castilla y León, vol. 1, pp. 31-56.

41. SAZ, I. La historiografía italiana y la guerra civil española. En: ARÓSTEGUI, J. (coord.), Historia y memoria de la guerra civil, 1988, Valladolid: Junta de Castilla y León, vol. 1, pp. 85-107.

42. SERRANO, C. La historiografía francesa y la guerra civil española. En: ARÓSTEGUI, J. (coord.), Historia y memoria de la guerra civil, 1988, Valladolid: Junta de Castilla y León, vol. 1, pp. 71-84.

43. BRADFORD, S. Documentation, 1948, London: Crosby Lockwood.

44. LOTKA, A.. J. The frequency distribution of scientific productivity. Journal of the Washington Academy of Sciences, 1926, vol. 16, $\mathrm{n}^{\circ}$ 12, pp. 317-323.

45. ROMÁN, V.; TUN̂́ÓN DE LARA, M. Spania eterna: novembrie 1936, batalla pentru Madrid. Magazin Historic, 1976, vol. 10, n. ${ }^{\circ}$, pp. 40-45.

46. VIÑAS, A. Gold, the soviet union and the spanish civil war. European Studies Review, 1979 , vol. 9 , n. ${ }^{\circ} 1$, pp. 105-128. 